\title{
Fuel spray vapour distribution for high pressure diesel fuel spray cases for different injector nozzle geometries.
}

\author{
Darlington Njere*, Nwabueze Emekwuru \\ Centre for Mobility and Transport, Faculty of Engineering, Environment and Computing, \\ Coventry University, Coventry CV12JH, UK \\ *Corresponding author: darlington.njere@coventry.ac.uk
}

\begin{abstract}
The evolution of diesel fuel injection technology, to facilitate strong correlations of in-cylinder spray propagation with injection conditions and injector geometry, is crucial in facing emission challenges. More observations of spray propagation are, therefore, required to provide valuable information on how to ensure that all the injected fuel has maximum contact with the available air, to promote complete combustion and reduce emissions. In this study, high pressure diesel fuel sprays are injected into a constant-volume chamber at injection and ambient pressure values typical of current diesel engines. For these types of sprays the maximum fuel liquid phase penetration is different and reached sooner than the maximum fuel vapour phase penetration. Thus, the vapour fuel could reach the combustion chamber wall and could be convected and deflected by swirling air. In hot combustion chambers this impingement can be acceptable but this might be less so in larger combustion chambers with cold walls. The fuel-ambient mixture in vapourized fuel spray jets is essential to the efficient performance of these engines. For this work, the fuel vapour penetration values are presented for fuel injectors of different k-factors. The results indicate that the geometry of fuel injectors based on the k-factors appear to affect the vapour phase penetration more than the liquid phase penetration. This is a consequence of the effects of the injector types on the exit velocity of the fuel droplets.
\end{abstract}

\section{Keyword}

Vapour, spray, k-factor, shadowgraph.

\section{Introduction}

Spray formation occurs with the introduction of liquid into a gaseous environment through an orifice such that the liquid breaks-up into droplets by interacting with the surrounding gases and causing its own unsteadiness [3]. For diesel engines, spray characteristics (liquid/vapour penetration and distribution) significantly affect the combustion and emission processes. By optimizing these characteristics, the tailpipe emissions, mainly oxides of Nitrogen $\left(\mathrm{NO}_{\mathrm{x}}\right)$ and partciculate matter (PM), can be minimized [2]. Spray penetration, which is usually analysed macroscopically, considers the development of the liquid and vapour components. It is desirable to achieve optimal travel of these spray components to avoid the adverse effects of impingement caused by under/overpenetration of liquid spray [19,20]. Advances in fuel injection system, with the introduction of the common rail technology, have provided increased controllability of the injection event.

The analyses of injection system development have been presented from several viewpoints. Nozzle geometry has been studied for the influence on the internal flow and spray characteristics with respect to: atomization [4,5], mixing processes [6,7], emission [9,10] and cavitation [8, 13]. Different injection strategies have been investigated to show the effect on pollutant emissions [2,3]. Specific studies have also been conducted with conical and cylindrical nozzles [11, 12], and to develop more understanding on the effects of nozzle holes [14-16] on spray characteristics. Many works in the literature also focused on parameters that affected spray penetration, whilst developing useful correlations [21, 22]. From these studies, it appears that the influence of nozzle geometry on spray characteristics has been established [7, 28]. Despite the comprehensive nature of these investigations, conducted using experimental/numerical methods under evaporative/non-evaporative conditions and often with the aid of optical techniques, the understanding is by no means complete and challenges not dismissed. The physics of the effects of nozzle geometry on in-cylinder spray development and combustion is still of interest to the research community and the auto-industry. For example, the survey in this work [7, 28], supported by other investigations [23, 24], clearly showed the significant effects of nozzle flow characteristics on spray development. This contrasts with other works $[25,26]$ which suggested negligible influence of nozzle flow characteristics over spray formation. Clearly, the true extent of the effect of nozzle geometry over a wide range of operating conditions and response variables need to be fully understood. Part of this uncertainty derives from unclear details about vaporisation, which is crucial for the injection process [27]. Since the vapor fuel continues to penetrate downstream while the liquid-phase fuel penetration stays at the liquid length, there is a correlation between the vapour penetration rate, total air entrainment rate and fuel-air mixing. Thus, depending on the injector geometry and the in-cylinder conditions, a higher vapour penetration may cause better air utilization, 
which affects the combustion process.

It is common to specify injector geometry based on the k-factor, this places emphasis on the hole diameter and its profound effect on fuel injection. Most injection characteristics change with the hole diameter. The k-factor can have a negative, zero or positive value. Spray hole (or orifice) with a negative conical shape factor exhibit an orifice with increasing diameter towards the nozzle exit. With a positive value of the conical shape factor, the orifice diameter decreases towards the exit (Figure 1). These two configurations implement a conical (or tapering) profile. A zero value for $\mathrm{k}$ (i.e. no conicity) indicates a cylindrical orifice since the diameters are equal. In this study, optical technique is applied to visualize in-cylinder spray penetration in the absence of a piston bowl, by implementing: high speed liquid spray visualization (Mie scattering technique) and vapour spray visualization using high-speed laser shadowgraph. Two injectors with different k-factors are utilized via a standard common rail system, and a low sulphur automotive diesel as the test fuel. It is expected that the result will be useful for vapour phase penetration modeling and for use in the validation of spray models.

$K=\frac{\left(D_{\text {inlet }}-D_{\text {outlet }}\right)}{10}$

Where $\mathrm{K}$ is the $\mathrm{k}$-factor, a measure of conicity; $\mathrm{Di}_{\text {nlet }}$ and $\mathrm{D}_{\text {outlet }}$ are inlet and outlet orifice diameters in micrometres $(\mu \mathrm{m})$, respectively.

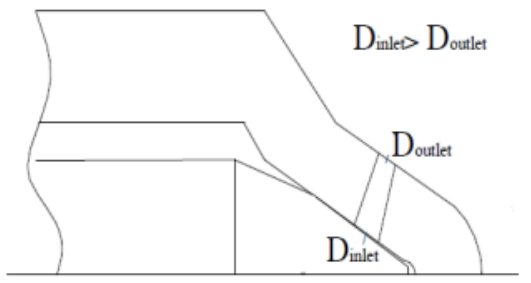

Figure 1: Nozzle configuration (Inlet/outlet diameter)

\section{Material and methods}

The liquid and vapour spray measurement systems were based on an optical engine, the Ricardo Proteus rig, installed at the University of Brighton, UK, where the tests were conducted under thermodynamic conditions similar to those found in a direct injection (DI) diesel engine. Optical diagnostics using high speed image acquisition equipment were developed and optimised around the Proteus, to visualise in-cylinder spray penetration. The Proteus is a 2-stroke, liner ported, single cylinder reciprocating rapid compression machine (RCM), with a specially designed head (top-hat shape and optical chamber with windows) for optical access. For the current study, steady in-cylinder (non-combusting) conditions were maintained all through the tests.

The injection system for this study was based on the high pressure (HP) common-rail system (CRS) fuel injection equipment on the Proteus rig using different injectors with key specifications summarised in Table 1. The Injectors have same hole diameters but different k-factors. Both injector types are classified by the k-factor parameter defined in equation (1). Only one, out of the four common rail injector outlets, was used at any given time, so the other unused three were fitted with plugs.

Table 1: Injector specifications

\begin{tabular}{|lrl|r|r|r|r|}
\cline { 3 - 7 } \multicolumn{1}{c|}{} & $\begin{array}{l}\text { Flow } \\
\text { (cc/min) }\end{array}$ & Holes & $\begin{array}{l}\text { Hole size } \\
(\mathbf{m m})\end{array}$ & $\begin{array}{l}\text { Cone angle } \\
\text { (deq.) }\end{array}$ & $\begin{array}{l}\text { k- } \\
\text { factor }\end{array}$ \\
\hline $\begin{array}{l}\text { Injector } \\
\text { 3601) } \\
\text { Injector } \\
\text { 3603) }\end{array}$ & 960 & 8 & & 0.137 & 155 & 1.3 \\
\hline
\end{tabular}

The optical arrangements were varied slightly between the liquid and vapour spray experiments, but similar steps were applied in setting-up. Engine logs were recorded with AVL Indiset high speed data acquisition system for fast logs (crank angle resolved), and EmTronics data logger for slow logs. For each regime of test, a minimum of fifty (50) videos were acquired with the laser/camera combination. The videos were post-processed with a Matlab software and analysed. In addition, the engine was stopped at intervals, during the tests, to clean the optical windows.

The liquid spray was visualised using the Mie scattering technique as shown in Figure 2. Here, the laser beam 
was aligned to pass through the vertical plane of the fuel spray and cause elastic scattering of the laser light by the liquid fuel droplets as soon as fuel was injected into the chamber. The high-speed camera was positioned perpendicular to the laser illumination to collect the scattered light. This visualised the liquid fuel distribution and showed the liquid spray penetration within the spray. The laser light was collimated before entering the optical engine, at reduced intensity via neutral density filters, by carefully placing the filter between the laser and a collimating lens. A slightly varied optical arrangement in Figure 3 implemented the shadowgraph technique for vapour spray visualisation

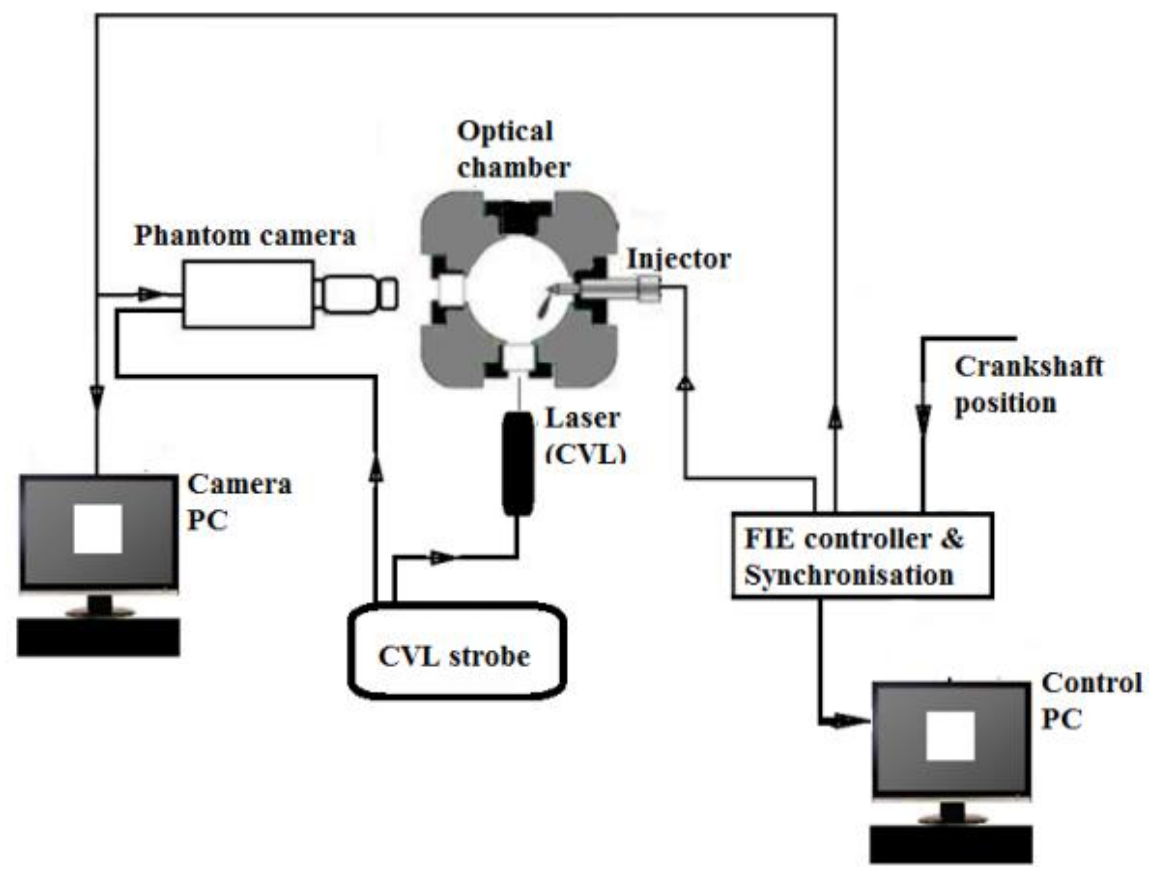

Figure 2: Schematic for Liquid spray visualisation

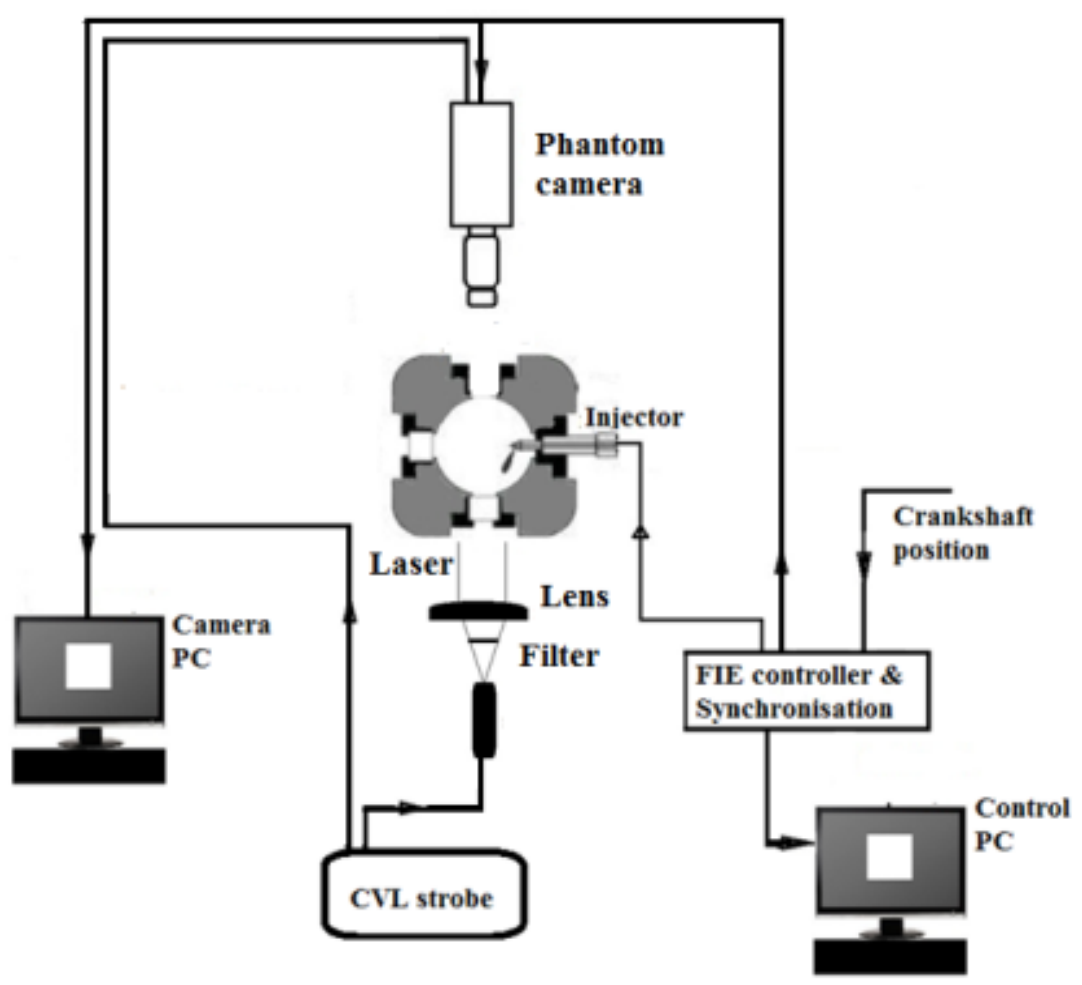

Figure 3: Set-up for vapour visualisation

Liquid and vapour spray penetrations were investigated with Injectors C and D respectively. The test conditions 
were selected from the matrix in Table 2, for investigations across injection pressure ranges (high, medium and low). While the test fuel used was Carcal RF06-08-B5 (density; $833.2 \mathrm{~kg} / \mathrm{m}^{3}$ ). Normal injection was timed at top dead centre (TDC). The actual intake air temperature was determined by the intake manifold temperature (TMAN), and hence varied significantly (less than $100^{\circ} \mathrm{C}$ ). Spray parameters were quantified with respect to time after start of injection (ASOI) for every spray plume.

Table 2: Test Matrix

\begin{tabular}{|r|r|r|r|r|}
\hline $\begin{array}{l}\text { Test } \\
\text { point } \\
(\text { TP) }\end{array}$ & $\begin{array}{c}\text { Intake air } \\
\text { temperature } \\
\text { TMAN }\left({ }^{\circ} \mathrm{C}\right)\end{array}$ & $\begin{array}{c}\text { Fuel } \\
\text { Peak in-cylinder } \\
\text { pressure ICP (bar) }\end{array}$ & $\begin{array}{c}\text { Injection } \\
\text { quantity } \\
\text { pressure } \\
\text { P (bar) }\end{array}$ & $\begin{array}{c}\left.\mathrm{mm}^{3}\right) @ 38 \\
{ }^{\circ} \mathrm{C}\end{array}$ \\
\hline 1 & 100 & 84 & 2000 & 65 \\
2 & 100 & 84 & 1600 & 36.31 \\
3 & 100 & 84 & 1400 & 36.71 \\
4 & 100 & 84 & 1000 & 35.31 \\
5 & 100 & 84 & 600 & 34.86 \\
6 & 100 & 50 & 2000 & 45 \\
7 & 100 & 50 & 1600 & 45 \\
8 & 100 & 50 & 1400 & 45 \\
9 & 100 & 50 & 1000 & 25 \\
10 & 100 & 66 & 2000 & 65 \\
11 & 100 & 66 & 1400 & 45 \\
12 & 100 & 66 & 1000 & 45 \\
13 & 100 & 79 & 1800 & 60 \\
14 & 100 & 73 & 1600 & 50 \\
15 & 100 & 40 & 600 & 20 \\
\hline
\end{tabular}

\section{Result and discussion}

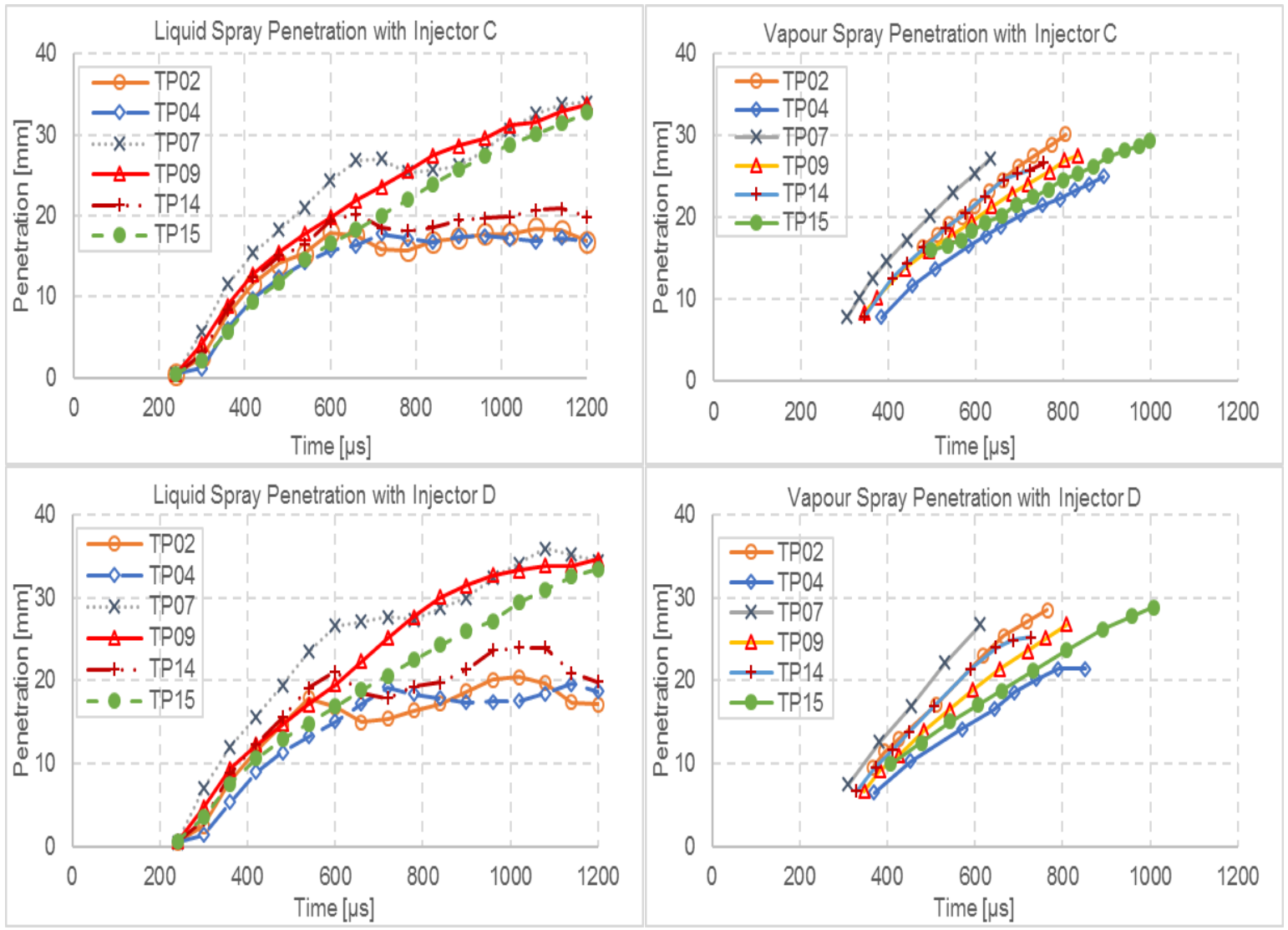

Figure 4: Comparison between injectors $C$ and $D$ spray (liquid and vapour) penetration measurements 

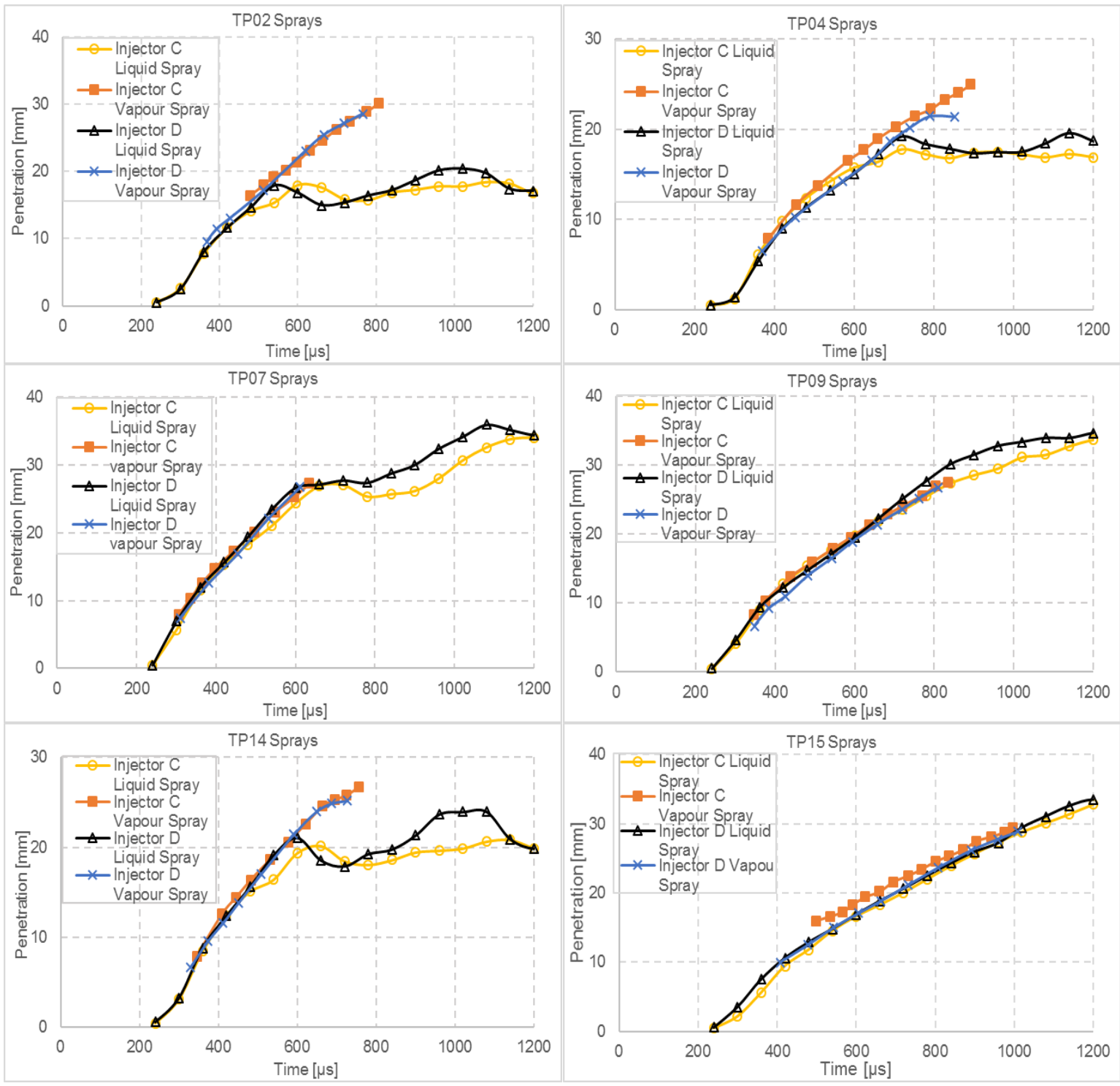

Figure 5: Comparison between injectors $C$ and $D$ spray (liquid and vapour) penetration measurements

Injector C

Injector D

TP04

TP14

TP15
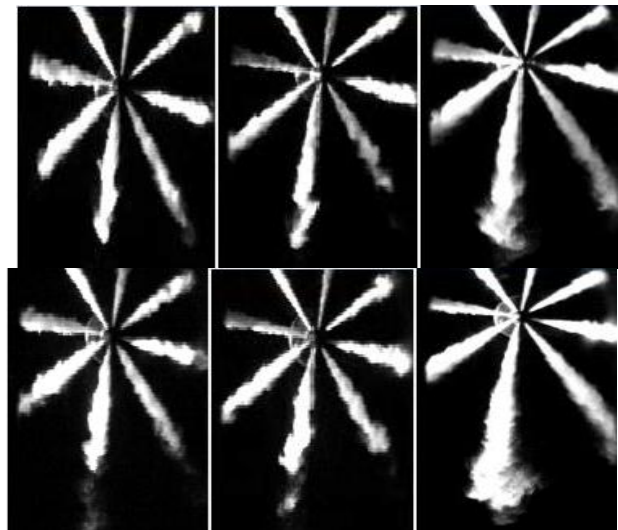

Figure 6: Image sequence for selected liquid spray penetration from all the injectors

Figures 4 and 5 show the results for the spray (liquid and vapour) penetration tests conducted with injectors $C$ and $D$ at Test Points selected from the matrix, for different injection pressures (low to high). Excerpt from the 
image sequence of liquid spray penetration from the injectors are presented in Figure 6.

In Table 1, the k-factor for injectors $C$ and $D$ were specified as: 1.3 and 3.5 respectively. Results from the plots and observations of the image sequence, which agree with literature, showed that nozzles with higher k-factor caused higher spray (liquid and vapour) penetration. It was also observed that the nozzle exit velocity and density increased with increase in conicity $[29,30]$ The results also showed that these behaviours were more evident under high (injection) pressures, as shown in Figures 4 and 5 for all the test points, except TP15 (with low pressures).

From the results, the effects of in-cylinder pressure on liquid spray penetration agree with previous investigations [21]. Increasing the ambient pressure increases the ambient temperature which causes the spray to evaporate faster and travel less. This trend is manifest even with increased injection pressure, especially for liquid spray penetration across the injectors. From the point of view of fluid dynamics, the evaporation of droplets involves simultaneous heat and mass transfer processes. The heat of evaporation is transferred from surrounding hot gases to the drop surface by conduction and convection, while vapour is transferred to the surrounding by convection and diffusion. The evaporation rate is dependent on the thermo-physical properties of the fuel and the surrounding air. For very high in-cylinder pressure and temperature, evaporation is quick since the latent heat drastically decreases for high temperatures. As the hot entrained air initiates evaporation of the spray, the fuel cools and contracts. These processes significantly reduce droplet dispersion and hence liquid spray penetration $[1,31]$. The effect of increased injection pressure, which increased spray velocity/momentum [21], is more noticeable in the transient part of the liquid spray penetration than the quasi steady stage. The slight positive slope observed at the steady period in some of the liquid penetration curves in Figures 4 and 5 can be attributed to two factors $[8,17]$. Firstly, the temperature of the fuel at the beginning of the injection is higher because the injector sac is always in direct contact with the high temperature gas of the combustion chamber; during the injection, the fuel flowing from upstream of the sac cools down the injector tip. This causes the temperature of the fuel at the orifice outlet to decrease during the injection, which impacts on liquid length [8]. Secondly, for long injections, low temperature fuel-air mix is re-entrained in the spray causing a decrease in the effective ambient temperature and an increment in liquid length. Taking the large size of the chamber into account as well as the tendency of the slope to decrease at the end of the injection, the first fact was generally considered to be responsible for the observed phenomenon.

The effect of increased injection pressure is clearer in the vapour penetration, which is further than the liquid spray travel [21]. Vapour penetration profiles have been shown to depend on both injection pressure and incylinder density [18]. It was further suggested that the mechanism for the vapour transport was the gas motion induced by the liquid phase momentum exchange, from the droplets to the gas phase. To support these facts, increased penetration of the vapour was observed at higher injection pressures and lower gas densities, which was when the liquid phase had a higher momentum. The momentum effect is felt more, across the injectors as the k-factor increases. The vapour spray penetrated more, at higher injection pressures (and higher ambient pressure), because the consequent level of turbulence was such that increased the hydrodynamic interaction of the spray. This process was facilitated by smaller nozzle exit as the k-factor increased. Primary breakup was accelerated leading to smaller droplets and reduced liquid spray penetration. The resulting increase in dispersion increases the vaporization rate and fuel air mixing.

Knowing that the k-factor could significantly affect vapour spray penetration is important for high speed direct injection (HSDI) diesel engine. Increase in vapour penetration improves mixing, results in greater premix burning and faster combustion, which may cause $\mathrm{NO}_{x}$ emission to increase, but reduce PM emissions.

\section{Conclusion}

The liquid and vapour phases of diesel fuel spray were characterised in this work, using optical techniques based on visualization. Mie-Scaterred and shadowgraph images were continuously recorded to expose liquid and vapour penetrations respectively, under real engine conditions. The injectors used were essentially different in terms of the k-factors. From the results, the significant influence of injector design (k-factor) on HSDI diesel engine spray development was confirmed. It was observed that the geometry of fuel injectors based on the kfactors affected the vapour phase penetration more than the liquid phase penetration. This was a consequence of the effects of the injector types on the exit velocity of the fuel droplets.

Further work could be done by replicating the characterisation experiments with piston bowl for impingement studies. The understanding from the present work will provide the necessary guidance and basis for comparison. The comparison of the data with commonly used correlations would provide further confidence on its use for spray model validations

\section{Acknowledgements}

Support for this work was provided by Ricardo UK, at Sir Harry Ricardo Laboratory in University of Brighton. Gratitude is also extended to: Prof. C. Crua, Dr. R. Morgan and Dr. G. de Sercey. 


\begin{tabular}{ll}
\multicolumn{2}{l}{ Nomenclature } \\
ASOI & After start of injection \\
CRS & Common-rail system \\
CVL & Copper vapour laser \\
D & Nozzle diameter $[\mu \mathrm{m}]$ \\
DI & Direct injection \\
HP & High pressure \\
HSDI & High speed direct injection \\
k & k-factor \\
NOx & Oxides of Nitrogen \\
PC & Personal computer (Dedicated desktop) \\
PM & Particulate matter \\
RCM & Rapid compression machine \\
TDC & Top dead centre \\
TMAN & Intake manifold temperature \\
TP & Test point
\end{tabular}

\section{References}

[1] Arcoumanis, C., C. Bae, R. Crookes and E. Kinoshita (2008). "The potential of di-methyl ether (DME) as an alternative fuel for compression-ignition engines: a review." Fuel 87: 1014-1030.

[2] Arrègle J, Pastor JV, López JJ, Garcı 'a A. (20028). Insights on post injection-associated soot emissions in direct injection diesel engines. Combust Flame154, 448-61.

[3] Suh HK, Yoon SH, Lee CS. (2010). Effect of multiple injection strategies on the spray atomization and reduction of exhaust emissions in a compression ignition engine fueled with dimethyl ether. Energy Fuels 24,1323-32.

[4] Yi Y, Reitz RD. (2003). Modeling the effect of primary atomization on diesel engine emissions. SAE Trans Sect 3 J Engines (SAE Paper 2003-01-1041)112, 1311-30.

[5] Som S, Aggarwal SK. (2010). Effects of primary breakup modeling on spray and combustion characteristics of compression ignition engines. Combust Flame 157,1087-96.

[6] Kampmann S, Dittus B, Mattes P, Kirner M. (1996). The influence of hydro grinding at VCO nozzles on the mixture preparation in a DI diesel engine. SAE Paper 960867

[7] Payri R, Salvador FJ, Gimeno J, Zapata DL. (2008). Diesel nozzle geometry influence on spray liquid-phase fuel penetration in evaporative conditions. Fuel 87, 1165-76.

[8] Payri F, Payri R, Salvador FJ, Martı 'nez-López J. (2012). A contribution to the understanding of cavitation effects in diesel injector nozzles through a combined experimental and computational investigation. Comput Fluids 58, 88-101

[9] Karra PK, Kong SC. (2010). Experimental study on effects of nozzle hole geometry on achieving low diesel engine emissions. J Eng Gas Turbine Power 132, 022802-11.

[10] Som S, Aggarwal SK, El-Hannouny EM, Longman DE. (2010). Investigation of nozzle flow and cavitation characteristics in a diesel injector. J Eng Gas Turbines Power 132, 2802-14

[11] Han J. S., Lu P-S., Xie X. B., Lai M. C. and Henein N. A. (2002). Investigation of Diesel Spray Primary Break-up and Development for Different Nozzle Geometries, SAE Paper 2002-01-2775

[12] Benajes J, Pastor JV, Payri R, Plazas AH. (2004). Analysis of the influence of diesel nozzle geometry in the injection rate characteristics. Journal of Fluids Eng, 126, 63-71.

[13] Payri R, Salvador F, Gimeo J, Venegas O. (2012). Study of Cavitation phenomenon using different fuels in a transparent nozzle by hydraulic characterization and visualisation. Experimental Thermal and Fluid Science 44, 235-244

[14] Zhang W, Nishida K, Gao J, Miura D. (2008). An experimental study on flat-wall impinging spray of microhole nozzles under ultra-high injection pressures, Proc. IMechE Part D J. Auto. Eng. 222 (9) 1731-41.

[15] Suh HK, Park SW, Lee CS. (2009). Effect of grouped-hole nozzle geometry on the improvement of biodiesel fuel atomization characteristics in a compression ignition engine, Proc. IMechE Part D J. Auto. Eng. 223 1587-1600.

[16] Karra PK, Kong SC. (2009). Experimental study on effects of nozzle hole geometry on achieving low diesel engine emissions, J. Eng. Gas Turbines Power 132 (2)

[17] Pickett, L. M., C. L. Genzale, G. Bruneaux, L.-M. Malbec, L. Hermant, C. Christiansen and J. Schramm (2010). Comparison of Diesel Spray Combustion in Different High- Temperature, High-Pressure Facilities. SAE Technical Paper 2010-01-2106.

[18] Crua, C. (2002). Combustion processes in a diesel engine. SCEM/CAE. University of Brighton, Brighton. Ph.D.: 271.

[19] Stanton DW, Lippert AM, Reitz RD, Rutland CJ. (1998). Influence of spray-wall interaction and fuel films on 
cold starting in direct injection diesel engines (SAE Paper 982584). SAE Trans J Fuels Lubric 107,1540-63

[20] Kashdan JT, Mendez S, Bruneaux G. (2007). On the origin of unburned hydrocarbon emissions in a wallguided, low NOx diesel combustion system (SAE 2007-01-1836). SAE Trans J Fuels Lubric 116, 234-57

[21] Naber JD and S. DL (1996). Effects of gas density and vaporization on penetration and dispersion of diesel sprays. SAE Paper 960034.

[22] Siebers DL. (1999). Scaling liquid-phase fuel penetration in diesel sprays based on mixing-limited vaporization (SAE Paper 1999-01-0528). SAE Trans J Engines 108, 703-28

[23] Morgan R, Wray J, Kennaird DA, Crua C, Heikal MR. (2001). The Influence of Injector Parameters on the Formation and break-Up of a Diesel Spray, SAE Technical Paper 2001-01-0529

[24] Zhang A, Montanaro A, Allocca L, Naber J, Lee S-Y. (2014). Measurement of Diesel Spray Formation and Combustion upon Different Nozzle Geometry using Hybrid Imaging Technique, SAE Paper 2014-01-1410

[25] Badock C, Wirth R, Tropea C. (1999). The influence of hydro grinding on cavitation inside a diesel injection nozzle and primary break-up under unsteady pressure conditions, in: Proc. 15th ILASS-Europe 99, Toulouse, July 5-7, Toulouse (France), 1999.

[26] Ganippa LC, Andersson S, Chomiak J, Matsson J. (2003). Combustion characteristics of diesel sprays from equivalent nozzles with sharp and rounded inlet geometries, Combustion Science and Technology 175 (6) 1015-32

[27] Lefebvre, A. H., (1989). Atomization and Sprays. Taylor \& Francis, ISBN 0-891116-603-3

[28] Som S, Ram'irez AI, Longman DE, Aggarwal SK. (2011). Effect of nozzle orifice geometry on spray, combustion, and emission characteristics under diesel engine conditions, Fuel 90 (3) (2011) 1267-76

[29] Petkar, R. M., C. A. Kardile, P. V. Deshpande, R. Isenburg and R. Soorajith (2004). Influence of Increased Diesel Fuel Spray Velocities and Improved Spray Penetration in DI Engines. SAE Paper 2004-010031.

[30] Montanaro, A., Allocca L, Johnson J, Lee S-Y, Naber J, Zhang A. (2013). Influence of the Nozzle Geometry of a Diesel Single-Hole Injector on Liquid and Vapor Phase Distributions at Engine-Like Conditions. SAE paper 2013-24-0038.

[31] Bougie, Tulej BM, Dreier T, Dam N, Meulen JT. Gerber T. (2005). "Optical diagnostics of diesel spray injections and combustion in a high-pressure high- temperature cell." Appl Phys B 80, 1039-1045. 